\title{
Genetic Heterology between Escherichia coli k12 and a Smooth Strain of $E$. coli
}

\author{
By L. ZUBRZYCKI AND SUSAN U. LEVINSON \\ Department of Microbiology, Temple University School of Medicine, \\ Philadelphia, Pennsylvania I9I40, U.S.A.
}

(Accepted for publication 20 March 1969 )

\begin{abstract}
SUMMARY
CF 2004-6, a recipient strain, and 04M 2, an Hfr donor strain of Escherichia coli $04: \mathrm{K}$ (undetermined): $\mathrm{H}_{5}$, were used in mating experiments with $E$. coli $\mathrm{K} 12.04 \mathrm{M} 2$ behaved like the $\mathrm{K} I 2$ donor strain in mating experiments. These donor strains genetically recombined with the $\mathrm{K} / 2$ recipient at higher frequencies than with CF 2004-6. The results of interrupted mating experiments were also more typical with the $\mathrm{K} I 2$ recipient than with CF 2004-6 in that there were sharp entry times for the markers studied and linear increases of recombinants with time. The possibility that host-controlled restriction decreased genetic recombination between $E$. coli $\mathrm{K}$ I2 and CF 2004-6 was pursued. We obtained no evidence for this possibility. Instead the data suggest that genetic heterology between these strains is affecting recombination. Genetic heterology also explains why $04 \mathrm{M} 2$ behaves more like a $\mathrm{K} 12$ donor in mating experiments with CF 2004-6.
\end{abstract}

\section{INTRODUCTION}

Smooth strains of Escherichia coli, i.e. those which are known to contain $\mathrm{O}$ and $\mathrm{K}$ antigens, can be sexually competent (Ørskov \& Ørskov, I961, 1966; Ketyi \& Szendrei, 1967). Many if not the majority of the freshly isolated strains used in early fertility surveys (Lederberg, Cavalli \& Lederberg, 1952; Furness \& Rowley, 1957) and more recently for transfer of a variety of plasmids (Meynell, Meynell \& Datta, 1968) were probably smooth. However, most of these strains were used only to establish donor or recipient ability or to study the transfer of a limited number of markers attached to the plasmids. When CF 2004-6, a strain of $E$. coli $04: \mathrm{K}$ (undetermined):H5, was shown to be a recipient (Zubrzycki \& Spaulding, I965) it became of interest to see how this typical smooth strain behaved in mating experiments. We found that it did not mate in broth, possibly because surface antigens prevented effective contact formation. The Millipore filter technique described in the Methods section allowed us to use CF 2004-6 in kinetic mating experiments. In preliminary work we became convinced that the genetic map of our smooth strain of $E$. coli would be similar to that established with K I 2 (Taylor \& Trotter, 1967). We did find that the recombination frequencies in $E$. coli $\mathrm{KI} 2 \times \mathrm{CF} 2004-6$ matings were lower than those in $\mathrm{KI} 2 \times \mathrm{KI} 2$ matings. Because host-controlled restriction is the cause of low recombination frequencies between $E$. coli $\mathrm{K} 12$, and $E$. coli B strains (Boyer, 1964; Copeland \& Bryson, 1966) and E. coli K 12 (PI) (Arber \& Morse, I965; Colson, Glover, Symonds \& Stacey, 1965), we decided to check whether it occurred in our studies. The data presented in this paper suggest that genetic heterology (some type of dissimilarity between DNA which 
hinders recombination) rather than restriction accounts for the low recombination frequencies between $E$. coli $\mathrm{K} 12$ and CF 2004-6 strains.

\section{METHODS}

Media. Penassay broth (antibiotic medium No. 3, Difco) was used for the cultivation of the organisms. The minimal agar was essentially the Davis minimal medium prepared as described by Lederberg (1950) except that it contained $0.5 \%$ glucose and approximately $\mathrm{I} \cdot 3 \%$ Noble agar (Difco). The amino acids were used at a concentration of 30 to $40 \mu \mathrm{g} . / \mathrm{ml}$. Streptomycin was used at a concentration of $500 \mu \mathrm{g} . / \mathrm{ml}$. to counterselect against the donor strains. Minimal enriched agar was minimal agar enriched with $0.2 \%$ Penassay broth.

Bacteria. Our recipient smooth strain of Escherichia coli is labelled CF 2004-6. Mutants of CF 2004-6 were isolated after treating a $24 \mathrm{hr}$ culture with $0 \cdot$ I M-ethyl methane sulfonate for I hr. An Hfr donor strain, O4M 2, of CF 2004-6 was obtained by selection for a terminal marker, lactose, in a mating between P $4 \times 6$ and Lac 6 . All these strains plus the $\mathrm{KI} 2$ strains are listed in Table $\mathrm{I}$.

Table r. Strains of Escherichia coli used

\begin{tabular}{ll}
$\begin{array}{c}\text { Strain } \\
\text { designation }\end{array}$ & \multicolumn{1}{c}{$\begin{array}{c}\text { Strain } \\
\text { origin }\end{array}$} \\
LZ-TM-6 & CF 2004-6 \\
LZ-TM-9 & CF 2004-6 \\
Lac 6 & CF 2004-6 \\
O4 M 2 & CF 2004-6 \\
P 4 X 6 & K I 2 \\
HfrH & K I2 \\
AB I I 33 & K I 2
\end{tabular}

\begin{tabular}{ll}
\multicolumn{1}{c}{ Characteristics* } & Sex \\
trp, leu, arg, his, pro, str-r & $\mathrm{F}^{-}$ \\
trp, leu, arg, his, thr, pro, str-r & $\mathrm{F}^{-}$ \\
trp, ilv, lac & $\mathrm{F}^{-}$ \\
trp, ilv & $\mathrm{Hfr}$ \\
met & $\mathrm{Hfr}$ \\
wild type & $\mathbf{H f r}$ \\
thr, leu, arg, his, pro, thi & $\mathrm{F}^{-}$ \\
mal, gal, lac, mtl, xyl, str-r &
\end{tabular}

* In the text, reference will also be made to the host-controlled restriction and modification locus which is designated as hsp (Taylor \& Trotter, 1967).

The order of transfer of markers from P $4 \times 6$ and $04 \mathrm{M} 2$ in a counterclockwise direction is 0 -pro-leu-thr-arg-his. . lac. The order of transfer of markers from $\mathbf{H f r H}$ in a clockwise direction is 0 -hsp-thr-leu-pro-his... arg.

Millipore filter matings. CF 2004-6 strains do not conjugate well in broth. We therefore modified the Millipore mating technique described by Matney \& Achenbach (1962) and Sanderson (1967). Overnight cultures of donor and recipient were diluted $\mathrm{I} / \mathrm{IOO}$ in Penassay broth. The female culture was incubated in a $37^{\circ}$ water bath shaker for $3 \mathrm{hr}$ and reached 5 to $8 \times 10^{8}$ viable bacteria per $\mathrm{ml}$. The donor culture was incubated for $3 \mathrm{hr}$ in a $37^{\circ}$ water bath without shaking and reached 3 to $5 \times 10^{8} / \mathrm{ml}$. Nine $\mathrm{ml}$. of the female culture and $\mathrm{I} \mathrm{ml}$. of the male culture were mixed. The female-male mixture was kept in an ice bath to prevent growth and mating. One $\mathrm{ml}$. samples were filtered on to $27 \mathrm{~mm}$. Millipore filters (type HA). The filter was transferred to $2 \mathrm{ml}$. of minimal glucose broth in a tube standing in a $37^{\circ}$ water bath. Timing started at this point. All matings were terminated by removing the tubes from the water bath, adding $8 \mathrm{ml}$. of ice-cold saline and agitating the tube on a Vortex Jun. mixer (maximum speed) for approximately 80 sec. Appropriate dilutions were made in saline and $0.1 \mathrm{ml}$. samples were placed into Petri dishes. Melted minimal agar kept at approximately $50^{\circ}$ was poured into each dish and mixed 
thoroughly with the $0 . \mathrm{I} \mathrm{ml}$. samples. After hardening, the agar plates were incubated at $37^{\circ}$ for $48 \mathrm{hr}$. This pour plating technique gave us higher recombinant frequencies and more reproducible results than spreading samples on the surface of agar.

Linkage analyses. Linkage between markers was calculated using the following formula:

no. recombinants for markers $a$ and $b$ no. recombinants for marker a

One tenth ml. samples of the recombinant mixture were plated in agar lacking one amino acid in order to determine the number of recombinants which received one marker and in agar lacking two amino acids for double recombinants. Susan U. Levinson (unpublished) found this technique gave results comparable to those obtained by selecting approximately 200 colonies and scoring for unselected markers on appropriate minimal agar. The frequencies obtained by this technique should be much more reliable because of the greater numbers involved in the analyses.

Marker stability of Escherichia coli recombinants. Unstable heterogenotes occur among hybrids of enteric bacilli (Falkow, Rownd \& Baron, 1962; Luria \& Burrous, 1957) and even among recombinants of Escherichia coli (Lederberg, 1949; Ketyi \& Szendrei, 1967). All recombinants to be used in backcrosses were tested for marker stability by streaking on minimal agar, incubating for $48 \mathrm{hr}$ and then restreaking on minimal enriched agar. Reconstruction experiments using known unstable $E$. coli K I 2-CF 2004-6 recombinants (none of which occurred in this study) showed that they grew out in 48 to $72 \mathrm{hr}$ as a mixture of regular sized and tiny colonies.

\section{RESULTS}

In preliminary mating experiments between Escherichia coli $\mathrm{K}$ I 2 and CF 2004-6 we found lac, pro, leu, thr, arg, ilv, mal, his and trp markers to be located in CF 2004-6 where expected, according to the genetic map established with E. coli $\mathrm{K} .12$ (Taylor \& Trotter, 1967). In addition to the linkages reported in detail here, we found $x y l$ closely linked to the str locus and $i l v$ to a rough locus, possibly the $E$. coli equivalent of the rou A locus described in Salmonella typhimurium (Subbaiah \& Stocker, 1964). These results convinced us that the genetic map of our smooth strain of $E$. coli was similar to that of E. coli K 12. However, genetic recombination in these inter-strain matings occurred at low frequencies. We decided to test whether host-controlled restriction could account for these low frequencies as it undoubtedly does in matings between rough strains of $E$. coli.

In matings involving the $\mathrm{K} 12$ donor $\mathrm{P} 4 \times 6$ and the CF 2004-6 recipient LZ-TM-6, one obtains lower recombinant frequencies and decreased linkage between markers when compared with an intra-strain $\mathrm{K} I 2 \times \mathrm{K} I 2$ mating using $\mathrm{AB} I \mathrm{I} 33$ as a recipient, Table 2 (crosses I and 2) and Table 3 (Test I). Since 04M 2 is a derivative of CF 2004-6, we now expected higher recombinant frequencies and increased linkage between markers when it conjugates with LZ-TM-6. The results (Table 2, crosses 3 and 4) show that except for the arginine marker $04 \mathrm{M} 2$ recombines with LZ-TM-6 and AB I I 33 at frequencies comparable to those using P $4 \times 6$ (crosses I and 2). Explanations for these results will be offered later, but at this time it should be pointed out that the higher recombinant frequency for arg indicates that the lower recombinant frequencies for other markers observed with LZ-TM-6 were not due to it being a poor recipient. The 
results of linkage analyses similarly show that $04 \mathrm{M} 2$ behaved like P4X6 (Table 3, Tests I and 2). The exception again was with the arg marker of LZ-TM-6 which showed increased linkage to pro (from 3.9 to $10 \%$ ) and leu (from 2.4 to $25 \%$ ) in matings with 04M2. The results of interrupted mating experiments (Fig. I to 4) are expressed using different scales because of the range in recombinant frequencies, but this cannot

Table 2. Recombinant frequencies after 100 min. matings

\begin{tabular}{|c|c|c|c|c|}
\hline \multirow[b]{2}{*}{ Cross } & \multirow[b]{2}{*}{ Donor $\times$ Recipient } & \multicolumn{3}{|c|}{ Percent recombinants per input donor } \\
\hline & & Pro $^{+}$ & $\mathbf{L e u}^{+}$ & $\mathrm{Arg}^{+}$ \\
\hline $\mathbf{I}$ & P4X6×ABII 33 & $23 \cdot 0$ & $27 \cdot 0$ & 0.32 \\
\hline 2 & P $4 \times 6 \times$ LZ-TM-6 & 0.22 & $2 \cdot 6$ & 0.26 \\
\hline 3 & $04 \mathrm{M} 2 \times$ AB I I 33 & $19 \cdot 0$ & $18 \cdot 0$ & 0.14 \\
\hline 4 & $04 M 2 \times L Z-T M-6$ & 0.42 & $\mathbf{2 \cdot 8}$ & $2 \cdot 6$ \\
\hline 5 & P $4 \times 6 \times 43$ & 0.23 & $4 \cdot 3$ & 0.25 \\
\hline 6 & P4X6× H I & - & $3 \cdot 8$ & 0.27 \\
\hline 7 & HfrH $\times$ AB I I 33 & $28 \cdot 0$ & $48 \cdot 0$ & - \\
\hline 8 & $\mathrm{HfrH} \times \mathrm{LZ}-\mathrm{TM}-6$ & $I \cdot 3$ & $2 \cdot 3$ & - \\
\hline 9 & $\mathbf{H f r H} \times \mathbf{H} 3$ & $6 \cdot 5$ & $8 \cdot 3$ & - \\
\hline 10 & $\mathbf{H f r H} \times \mathbf{H} \mathbf{I}$ & - & $6 \cdot 6$ & - \\
\hline I I & P $4 \times 6 \times 44$ & $8 \cdot 8$ & $2 \cdot 9$ & 0.27 \\
\hline
\end{tabular}

The average recombinant frequencies from repeat mating experiments is shown in crosses $1,2,3$, 4,7 and 8. Only the average recombinant frequencies from backcrosses with individual $\mathrm{K}$ I 2-CF 2004-6 hybrids is shown in crosses $5,6,9$, Io and I I because the individual frequencies varied no more than those observed in repeat mating experiments using the Millipore technique as described in the Methods section.

Table 3. Linkage from roo min. inter- and intra-strain matings

\begin{tabular}{|c|c|c|c|c|c|c|c|}
\hline \multirow[b]{3}{*}{ Donor } & \multirow[b]{3}{*}{ Test } & \multicolumn{6}{|c|}{ Recipient } \\
\hline & & \multicolumn{2}{|c|}{ Pro } & \multicolumn{2}{|c|}{ Leu } & \multicolumn{2}{|c|}{ Arg } \\
\hline & & AB I I 33 & LZ-TM-6 & AB I I 33 & LZ-TM-6 & AB I I 33 & LZ-TM-6 \\
\hline$P 4 \times 6$ & I & $\begin{array}{r}100 \cdot 0 \\
58 \cdot 0 \\
30 \cdot 0\end{array}$ & $\begin{array}{r}100 \cdot 0 \\
4.3 \\
2.8\end{array}$ & $\begin{array}{r}48 \cdot 0 \\
100 \cdot 0 \\
37.0\end{array}$ & $\begin{array}{r}31 \cdot 0 \\
100 \cdot 0 \\
12.0\end{array}$ & $\begin{array}{c}0 \\
I \cdot 0 \\
100 \cdot 0\end{array}$ & $\begin{array}{r}3.9 \\
2.4 \\
100.0\end{array}$ \\
\hline $04 M 2$ & 2 & $\begin{array}{r}100.0 \\
62.0 \\
33.0\end{array}$ & $\begin{array}{r}100 \cdot 0 \\
6.3 \\
I .8\end{array}$ & $\begin{array}{r}45^{\circ} 0 \\
100^{\circ} 0 \\
34^{\circ} 0\end{array}$ & $\begin{array}{r}32 \cdot 0 \\
100 \cdot 0 \\
16 \cdot 0\end{array}$ & $\begin{array}{c}0 \\
I \cdot 0 \\
100 \cdot 0\end{array}$ & $\begin{array}{r}10 \cdot 0 \\
25.0 \\
100 \cdot 0\end{array}$ \\
\hline HfrH & 3 & $\begin{array}{r}100 \cdot 0 \\
67.0\end{array}$ & $\begin{array}{r}100 \cdot 0 \\
47.0\end{array}$ & $\begin{array}{r}83.0 \\
100 \cdot 0\end{array}$ & $\begin{array}{r}53.0 \\
100.0\end{array}$ & - & - \\
\hline
\end{tabular}

Only the average per cent linkages from backcrosses with different hybrids is shown because the individual results did not vary much from the average. The per cent linkage between two markers was determined by comparing the number of recombinants which received the two markers to those which received one of the markers which is expressed in the table as $100 \%$. This was done after a 100 min. mating by plating aliquots of the recombinant mixture in agar lacking two amino acids in order to determine the number of double recombinants and in agar lacking one amino acid for single recombinants.

affect the interpretation of the data which show the appearance of markers at about the same time in each cross. Note the non-linear appearance of markers in Fig. 3 and 4. The non-linear appearance of markers during conjugation was shown to be associated with host-controlled restriction by Copeland \& Bryson (I966). However, the same type of curve has even been observed between Escherichia coli K I 2 strains, P 4 X 6 and 
AB I I33 (Schneider \& Falkow, I964). Therefore, a non-linear curve is no indication that restriction is occurring. The great delay in the appearance of markers observed by Boyer (1964) is an obvious manifestation of restriction, but this did not occur in our crosses. Nevertheless, host-controlled restriction could still account for the lower recombinant frequencies and reduced linkages obtained wtih LZ-TM-6. If this is so,

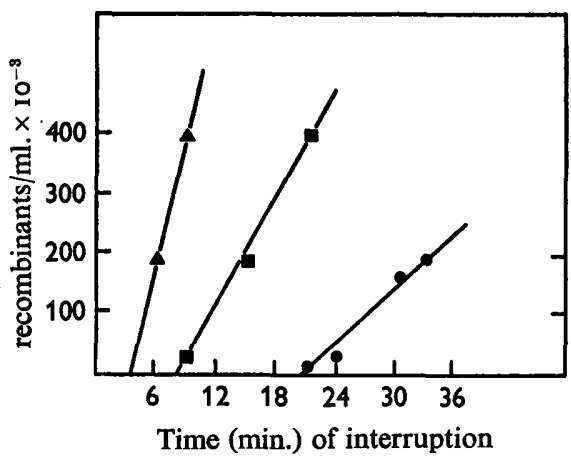

Fig. I
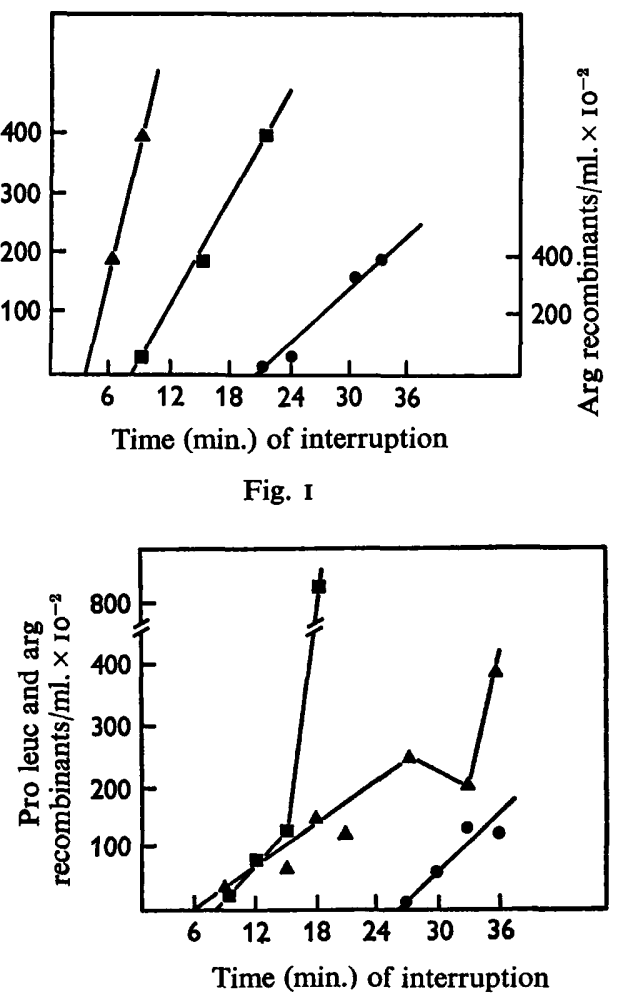

Fig. 3



Fig. 2

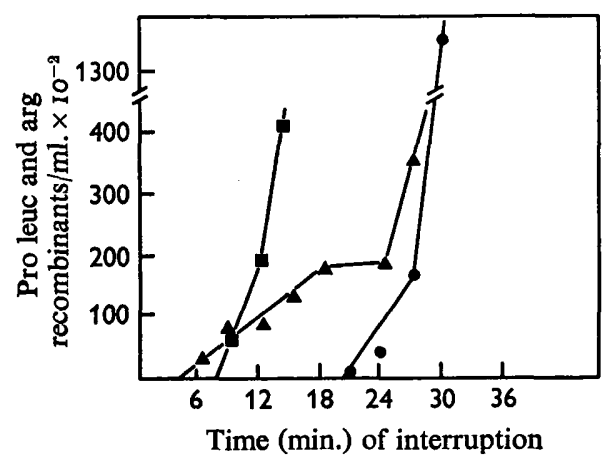

Fig. 4

Fig. I. Interrupted mating experiment between $P 4 \times 6$ and $A B$ I 133. One ml. mixtures of log. phase donor $\left(3\right.$ to $5 \times 10^{7} \mathrm{ml}$.) and recipient $\left(5\right.$ to $8 \times 10^{8} / \mathrm{ml}$.) cultures were filtered on to Millipore filters. The filters were placed in tubes containing minimal glucose broth which were incubated at $37^{\circ}$. At time intervals cold saline was added to the tubes which were then shaken on a Vortex Jun. mixer in order to interrupt the matings. Samples were now plated in order to select for $\mathrm{Pro}^{+}(\mathbf{A - \Delta}), \mathrm{Leu}^{+}(\mathbf{\square -})$ and $\mathrm{Arg}^{+}\left(\mathrm{O}_{-}\right)$recombinants.

Fig. 2. Interrupted mating experiment between $04 \mathrm{M} 2$ and $\mathrm{ABIII3}$. Pro ${ }^{+}(\Delta-\Delta)$, Leu ${ }^{+}$ (一-D) and $\mathrm{Arg}^{+}\left(\mathrm{O}_{-}-\mathrm{O}\right)$ recombinants. For details see Fig. I.

Fig. 3. Interrupted mating experiment between $\mathrm{P} 4 \times 6$ and $\mathrm{LZ}-\mathrm{TM}-6$. $\mathrm{PrO}^{+}(\Delta-\Delta), \mathrm{Leu}^{+}$ (1-) and $\mathrm{Arg}^{+}(-)$recombinants. For details see Fig. I.

Fig. 4. Interrupted mating experiment between $04 \mathrm{M} 2$ and $\mathrm{Lz}-\mathrm{TM}-6$. $\mathrm{Pro}^{+}(\Delta-\Delta), \mathrm{Leu}^{+}$ $(\square-b)$ and $\mathrm{Arg}^{+}(\odot-)$ recombinants. For details see Fig. I.

then incorporation in a CF 2004-6 recipient of the $\mathrm{K} I 2$ host-controlled restriction and modification locus (K I 2-hsp locus) should make them appear more $\mathrm{K}$ I 2-like in matings. This work was pursued using only K I2 donor strains since we knew that restriction and modification occur with $\mathrm{K} I 2$ strains. The approach we took was similar to that 
used by Boyer (I964), who found linkage between the hsp locus and the thr marker. An $\mathrm{HfrH} \times \mathrm{LZ}-\mathrm{TM}-9$ mating was interrupted at 6, 9 and $\mathrm{I} 2 \mathrm{~min}$. From the various time intervals a total of eighteen $\mathrm{Thr}^{+}$recombinants (labelled $\mathrm{H}_{3}$ ) was isolated. The recombinants were checked for stability and then backcrossed with P4X6 (Table 2, cross 5). There was no marked increase in recombinant frequencies for pro or arg when compared to the results shown in cross 2 , but there did seem to be a slight increase for leu. Linkage analyses were done on all crosses (Table 4, Test I with $\mathrm{H}_{3}$ ). Compared to the results using LZ-TM-6 (Table 3, Test I with LZ-TM-6), there was an increase in linkage for leu both among $\mathrm{Pro}^{+}$(from $3 \mathrm{I}$ to $58 \%$ ) and $\mathrm{Arg}^{+}$(from 12 to $26 \%$ ) recombinants. That these slight increases for leu recombination and linkage may not be specifically related to the $\mathrm{K} 12-h s p$ locus is suggested by the following experi-

Table 4. Linkage from roo min. backcrosses with recipient KI2-CF2004-6 hybrids

\begin{tabular}{|c|c|c|c|c|c|c|c|c|c|}
\hline \multirow[b]{3}{*}{ Donor } & \multirow[b]{3}{*}{ Test } & \multicolumn{8}{|c|}{ Recipient } \\
\hline & & \multicolumn{2}{|c|}{ Pro } & \multicolumn{3}{|c|}{ Leu } & \multicolumn{3}{|c|}{ Arg } \\
\hline & & H3 & $\mathrm{H} 4$ & H3 & H I & H4 & H 3 & H I & H4 \\
\hline P $4 \times 6$ & I & $\begin{array}{r}100 \cdot 0 \\
2 \cdot 9 \\
1 \cdot 7\end{array}$ & $\begin{array}{l}- \\
43 \cdot 0 \\
19.0\end{array}$ & $\begin{array}{r}58 \cdot 0 \\
100 \cdot 0 \\
26 \cdot 0\end{array}$ & $\frac{-}{23 \cdot 0}$ & $\begin{array}{r}- \\
100 \cdot 0 \\
20 \cdot 0\end{array}$ & $\begin{array}{r}2 \cdot I \\
I \cdot 7 \\
100 \cdot 0\end{array}$ & $\frac{-}{100 \cdot 0}$ & $\begin{array}{r}{ }_{\mathrm{I} \cdot 3} \\
\mathrm{IOO} \cdot 0\end{array}$ \\
\hline HfrH & 2 & $\begin{array}{r}100^{\circ} \\
43^{\circ}\end{array}$ & - & $\begin{array}{r}68 \cdot 0 \\
100 \cdot 0\end{array}$ & $\overline{-}$ & - & - & $=$ & - \\
\hline
\end{tabular}

Only the average per cent linkages from backcrosses with different hybrids is shown because the individual results did not vary much from the average. The per cent linkage between two markers was determined by comparing the number of recombinants which received the two markers to those which received one of the markers which is expressed in the table as $100 \%$. This was done after a $100 \mathrm{~min}$. mating by plating samples of the recombinant mixture in agar lacking two amino acids in order to determine the number of double recombinants and in agar lacking one amino acid for single recombinants.

ments. A P4X6×LZ-TM-6 conjugation was interrupted at 6 and $9 \mathrm{~min}$. in order to get $\mathrm{Pro}^{+}$recombinants. Eleven $\mathrm{Pro}^{+}$recombinants (labelled $\mathrm{HI}$ ) were isolated, checked for stability, found to be leu negative and presumed to be K I2-hsp negative since this locus is even distal to leu. The recombinant frequencies from backcrosses with $\mathrm{P} 4 \times 6$ and these recombinants are shown in Table 2. Compared to the results using LZ-TM-6 (cross 2), backcrosses using $\mathrm{HI}$ (cross 6) resulted in a slight increase for $\mathrm{Leu}^{+}$recombinants similar to that using $\mathrm{H}_{3}$ (cross 5). Since $\mathrm{Hr}$ is $\mathrm{Pro}^{+}$, the only linkage determined was that between arg and leu which is shown in Table 4 (Test I with $\mathrm{H} \mathrm{I}$ ). Compared to the results using LZ-TM-6 (Table 3, Test I with LZ-TM-6), there was a slight increase in this linkage (from $\mathrm{I} 2$ to $23 \%$ ) similar to that observed with the $\mathrm{H} 3$ recipients (from I 2 to $26 \%$ ). Another E. coli $\mathrm{K} \mathrm{I} 2$ donor strain, $\mathrm{HfrH}$, was used in experiments similar to those just described for $\mathrm{P} 4 \times 6$. The recombinant frequencies in inter-strain matings were considerably lower than those in intra-strain matings as shown in Table 2 (crosses 7 and 8). In spite of this, linkage between pro and leu in the inter-strain matings was not greatly affected (Table 3, Test 3, compare the results using AB I I 33 and LZ-TM-6). Backcrosses with six $\mathrm{H} 3$ recombinants resulted in some increase in recombinant frequencies for pro and leu (Table 2, compare crosses 8 and 9). Linkage analyses on these backcrosses are shown in Table 4 (Test 2 with H3). Compared to the 
results using LZ-TM-6 (Table 3, Test 3 with LZ-TM-6), selection for the distal marker pro resulted in an increase in linkage with leu (from 53 to $68 \%$ ). However, when selecting for the proximal marker leu there was no increase in linkage. $\mathrm{HfrH}$ was also backcrossed with three H I recombinants. Compared to the results using LZ-TM-6 (Table 2, cross 8 ), backcrosses using $\mathrm{H} \mathrm{I}$ (cross 10 ) resulted in a slight increase for $\mathrm{Leu}^{+}$recombinants similar to that using $\mathrm{H}_{3}$ (cross 9). Since $\mathrm{H} \mathrm{I}$ is $\mathrm{PrO}^{+}$, the recombinant frequency and linkage for this marker could not be determined.

In all these backcrosses using KI2-CF 2004-6 recombinants slight increases in recombinant frequencies and linkage could be associated with the incorporation of the K I2-thr marker which is closely linked to the K I 2-hsp locus. But that does not mean that the K I2-hsp locus is functioning in CF 2004-6 because similar increases were also found with recombinants which contained a $\mathrm{K} \mathrm{I} 2$ region (pro) not closely linked to the K I2-hsp locus. Our interpretation for these slight increases is that the presence of a piece of $\mathrm{K} I 2$ DNA in CF 2004-6 increases the chances of crossing over between this $\mathrm{K} I 2$ DNA and the homologous DNA region in the $E$. coli $\mathrm{K} 12$ donor, thus increasing genetic recombination. Take, for example, the results obtained from matings between $E$. coli $\mathrm{K} \mathrm{I}_{2}$ and $\mathrm{H}_{3}$. The slight increases for $\mathrm{Leu}^{+}$recombinant frequency and linkage are probably due to the presence of the adjacent $\mathrm{K} I 2 \mathrm{thr}$ region in $\mathrm{H} 3$. To support this interpretation we present the results of backcrosses with two typical $\mathrm{H}$ I recombinants which were mutated at the $\mathrm{K} I 2$ pro region (labelled $\mathrm{H} 4$ ). Backcrosses involving $\mathrm{P}_{4} \times 6$ and 44 show a higher Pro ${ }^{+}$recombinant frequency when compared with a mating using LZ-TM-6 (Table 2 , crosses 2 and II). Linkage analyses on these crosses are shown in Table 4 (Test $\mathrm{I}$ with $\mathrm{H} 4$ ). Compared to the results using LZ-TM-6 (Table 3, Test I with LZ-TM-6), there was an increase in linkage for pro (from 4.3 to $43 \%$ ) when selecting for leu and increases for pro (from 2.8 to $19 \%$ ) and leu (from I 2 to $20 \%$ ) when selecting for arg. These results show that areas of DNA homology do increase the chances of recombination between strains of $E$. coli.

\section{DISCUSSION}

The data presented in this paper suggest that restriction plays no obvious role in genetic recombination between Escherichia coli $\mathrm{K} I 2$ and CF 2004-6 strains for the following reasons. In spite of lower recombinant frequencies and decreased linkage between genes, there was no delay in appearance of markers. Backcrosses with eighteen $E$. coli $\mathrm{K} \mathrm{I2-CF} \mathrm{2004-6}$ recombinants which received the $t h r$ locus and presumably the $\mathrm{K}$ I2-hsp locus from $\mathrm{HfrH}$ showed no more of an increase in recombinant frequencies and linkage than did backcrosses with recombinants which received from $P 4 \times 6$ the pro locus, which is not linked to $h s p$.

Boyer (1964) found that the K 12-hsp locus was incorporated along with the thr marker in $60 \%$ of the Escherichia coli $\mathbf{B} / \mathbf{R}$ recombinants. It may be argued that this and linkage is greatly reduced in CF 2004-6 strains. As shown in Table 3, linkage of leu pro in $\mathrm{HfrH} \times \mathrm{CF} 2004-6$ matings was decreased not even twofold when compared with linkage in $\mathrm{HfrH} \times \mathrm{ABI} I 33$ matings. This difference is even less than that reported for the same two markers in $E$. coli $\mathrm{HfrH} \times \mathrm{B} / \mathrm{R}$ matings (Boyer, 1964). Therefore, it seems likely that the closely linked markers, $h s p$ and $t h r$, would both be incorporated in CF 2004-6 in as high a percentage of cases as they were in E. coli $\mathrm{B} / \mathrm{R}$.

We attribute the lower recombination frequencies to genetic heterology between 
Escherichia coli $\mathrm{KI} 2$ and CF 2004-6 and the increase in these frequencies upon backcrossing with these inter-strain recombinants to the artificially established genetic homology. This interpretation is the same as that invoked by Johnson, Falkow \& Baron (1964) to explain the lower recombination frequencies between $E$. coli and Salmonella typhi and the increase in frequencies upon rematings with hybrids. Genetic heterology can also be used to explain why $E$. coli 04 M 2, an Hfr derivative of CF 2004-6, gives higher recombination frequencies with the $K I 2$ recipient than with $C F$ 2004-6. In deriving this strain (see Methods), not only did the $E$. coli $\mathrm{K} I 2$ lac region and the F factor become incorporated into the CF 2004-6 genome but possibly the pro to leu region as well. The arg region did not, and that is why there is more genetic recombination for this region between 04M2 and CF 2004-6. This hypothesis is supported by experiments (unpublished) in which we use transductions by $\Phi$ ०4-CF to distinguish between the genes of $E$. coli K I2 and CF 2004-6 (Zubrzycki \& Gainsburg, 1966).

During the process of the work reported here, we realized that the restriction mechanism is probably a surface phenomenon (Schell \& Glover, 1966). In this regard, it was suggested that the Millipore mating technique, by artificially forcing bacteria together, bypassed the normal surface opposition of donor and recipient and consequently the restriction mechanism. We obtained $E$. coli $\mathrm{B} / \mathrm{R}$ strains from Boyer and demonstrated that our mating technique would allow the restriction mechanism to be expressed. We also proved with his strains that our laboratory strain of $\mathrm{HfrH}$ contained and could successfully transmit the $\mathrm{K} 12-h s p$ locus to $E$. coli $\mathrm{B} / \mathrm{R}$. We also entertained the possibility that the surface antigens on our smooth strain may be interfering with a surface phenomenon such as restriction. We isolated four rough strains of LZ-TM-6. In preliminary experiments we did not observe restriction during conjugation. These experiments were discontinued when a complete host-controlled restriction and modification system was discovered in our smooth strains (to be published). This system is accompanied by radical effects on genetic recombination and, restriction and modification of phage Ф04-CF (Zubrzycki, Green \& Spaulding, 1966). Preliminary experiments with this $E$. coli 04 restriction and modification system prove that the K-I2 hsp locus is closely linked to $t h r$ in matings with CF 2004-6. However, in the experiments reported here the $\mathrm{K} 12-h s p$ locus could not function in CF 2004-6. It has been speculated that the restriction and modification phenomenon is of benefit to a strain of bacterium because it allows genetic exchange with its own strain but prevents it with another (Wood, 1966). The results presented in our studies suggest that the occurrence of restriction and modification in genetic experiments between bacterial strains is unpredictable and the true evolutionary value of the phenomenon is obscure.

The authors acknowledge the technical assistance of Sharon K. Gainsburg and Joan Press during portions of this work, and thank Dr Herbert Boyer, San Francisco Medical Center, San Francisco, U.S.A., for his Escherichia coli B/R strains.

This work was supported by grant AI-0658I from the National Institute of Allergy and Infectious Diseases, U.S. Public Health Service, Bethesda, Maryland. 


\section{REFERENCES}

ARBER, W. \& MORSe, M. L. (1965). Host specificity of DNA produced by Escherichia coli. VI. Effects on bacterial conjugation. Genetics, Princeton 51, 137.

BOYER, H. (1964). Genetic control of restriction and modification in Escherichia coli. J. Bact. 88, 1652.

Colson, C., Glover, S. W., Symonds, N. \& Stacey, K. A. (1965). The location of the genes for host-controlled modification and restriction in Escherichia coli $\mathrm{K} 12$. Genetics, Princeton 52, 1043.

Copeland, J. C. \& BRYson, V. (1966). Restriction in matings of Escherichia coli strain $\mathrm{K} 12$ with strain B. Genetics, Princeton 54, 44I.

FALKow, S., ROWND, R. \& BARON, L. S. (1962). Genetic homology between Escherichia coli $\mathrm{K} 12$ and Salmonella. J. Bact. 84, 1303.

FURNESS, G. \& ROWLEY, D. (1957). The presence of transmissible agent $F$ in non-recombining strains of E. coli. J. gen. Microbiol. 17, 550 .

Johnson, E. M., FALKow, S. \& BARON, L. S. (1964). Recipient ability of Salmonella typhosa in genetic crosses with Escherichia coli. J. Bact. 87, 54.

KETYI, I. \& SZENDREI, L. (1967). The fertility of Escherichia coli oIOI: K(A)30:-strain I8A IO in mating with Escherichia coli $\mathrm{K} 12$. Acta microbiol. hung. 14, 173.

LeDerberg, J. (1949). Aberrant heterozygotes in Escherichia coli. Proc. natn. Acad. Sci. U.S.A. 35, 178.

LEDERBERG, J. (1950). Isolation and characterization of biochemical mutants of bacteria. Meth. med. Res. 3, 5.

Lederberg, J., Cavalli, L. \& Lederberg, E .(I952). Sex compatibility in Escherichia coli. Genetics, Princeton 37, 720.

Luria, S. E. \& Burrous, J. W. (1957). Hybridization between Escherichia coli and Shigella. J. Bact. 74, 46I.

Matney, T. S. \& Achenbach, N. E. (1962). A comment on the fertility of $F_{2}$ donor types of $E$. coli K I2. Biochim. biophys. Res. Commun. 9, 285.

Meynell, E., Meynell, G. G. \& Datta, N. (1968). Phylogenetic relationships of drug-resistance factors and other transmissible bacterial plasmids. Bact. Rev. 32, 55 .

$\emptyset_{\mathrm{RSKOV}}, \mathrm{F}$. \& ØRSkov, I. (196I). The fertility of Escherichia coli test strains in crosses with $\mathrm{K} I 2$. Acta path. microbiol. scand. 51, 280.

ØRSKOV, I. \& ØRSKOV, F. (I966). Episome-carried surface antigen K 88 of Escherichia coli. J. Bact. 9x, 69.

SANDERSON, K. E. (1967). Revised linkage map of Salmonella typhimurium. Bact. Rev. 31, 354.

SCHELl, J. \& Glover, S. W. (1966). The effect of various physiological conditions on host-controlled restriction in E. coli $\mathrm{K}(\mathrm{PI})$. Genet. Res. 7, 273.

SCHNEIDER, H. \& FALKow, S. (1964). Characterization of an Hfr strain of Shigella flexneri. J. Bact. 88,682 .

Subbaiah, T. V. \& Stocker, B. A. D. (1964). Rough mutants of Salmonella typhimurium. I. Genetics. Nature, Lond. 201, 298.

TAYLOR, A. L. \& Trotrer, C. S. (1967). Revised linkage map of Escherichia coli. Bact. Rev. 31, 332.

Wood, W. B. (1966). Host specificity of DNA produced by Escherichia coli: Bacterial mutations affecting the restriction and modification of DNA. J. molec. Biol. r6, I88.

ZUBRZYCKI, L. \& GAINSBURG, S. (1966). Genetic homology of mutant markers determined by transduction. Bact. Proc. 31.

ZubrzYCKI, L. \& Spaulding, E. H. (1965). Genetic heterogeneity between Escherichia coli strains. Bact. Proc. p. 142.

Zubrzycki, L., Green, J. \& Spaulding, E. H. (I966). A generalized transducing phage for a female Escherichia coli 04 . J. gen. Microbiol. 45, I 13. 